\title{
A política externa dos Estados Unidos: da primazia ao extremismo
}

\author{
CESAR GUIMARÃES
}

$\mathrm{D}$ ATA DO INÍcio da década de 1990 o trabalho de Samuel Huntington utilizando a noção primacy (primazia), que começava a ter uso corrente na "comunidade estratégica" dos Estados Unidos. O artigo apreciava as relações econômicas com o Japão, que então preocupavam o governo Clinton, mas as implicações conceituais eram mais amplas e justificam a seguinte citação, algo longa:

É errôneo pensar que a principal razão pela qual os Estados buscam a primazia internacional consiste em capacitar-se para vencer guerras e que, portanto, se uma guerra é improvável, a primazia não é importante. Os Estados buscam a primazia para manter a sua segurança, promover seus interesses e conformar o ambiente internacional de forma a refletir os interesses e valores deles. Ela é desejável não fundamentalmente para obter vitória em uma guerra, mas para alcançar os objetivos do Estado sem recurso a ela. A primazia é, pois, uma alternativa à guerra (Huntington, 1993) (1).

Até aqui Tucídides e seu notável tradutor inglês, Hobbes, demonstrariam complacência no entendimento do ponto, mas decerto teriam maiores dificuldades em acompanhar o autor em sua conclusão: a primazia norte-americana não apenas serve ao seu país, mas também "ao futuro da liberdade, da democracia, de economias abertas e da ordem internacional do mundo" (idem).

Data da mesma época a difusão da noção de "unipolaridade", a partir de trabalho de um analista político do New York Times (Krauthammer, 1991). A noção, digamos assim, "pegou", incentivando uma enorme indústria de artigos. Sua "afinidade eletiva" com a "primazia" é óbvia, e mais o fica na principal antologia que lhe é dedicada, cujo prefácio rende forte homenagem a Huntington (Kapstein e Mastandumo, 1999).

A unipolaridade "benigna" - que já aparece em Huntington - e a primazia que nem sempre diz seu nome são noções teórico-ideológicas interessantes para tentar compreender a passagem do "fim da Guerra Fria", com o primeiro Bush, aos governos de Clinton e do segundo Bush - este último, o objeto da parte final do presente trabalho. 
Sem a Guerra Fria, como justificar, interna e externamente, a política externa expansionista dos três governos?

“Os Estados Unidos encontravam extremas dificuldades para definir seus 'interesses nacionais' diante da ausência do poderio soviético", afirma Condoleezza Rice, em seu artigo originariamente publicado em fevereiro de 2000, plataforma de política externa do futuro governo de George W. Bush (Rice, 2001).

O artigo da atual assessora para Assuntos de Segurança Nacional do governo americano é uma formulação a que não falta brilho, mas, nesta passagem, repete um lugar comum de natureza estritamente ideológica. Pois o "interesse nacional" (um termo recuperado também nos de 1990) não se alterou profundamente desde meados do século passado. O que, sim, passou a necessitar de reformulação foi a rationale para as ações pertinentes.

A grande número de estudiosos de relações internacionais incomoda o lançar mão do conceito de legitimidade - afinal, no limite, a "anarquia" do sistema clama pelo poder em seu sentido mais explícito. Weber refere-se à importância do apresentar-se como legítimo quer no quadro administrativo de uma ordem política, quer junto dos governados. Não é de todo errôneo substituir, no plano internacional, o "quadro administrativo" pelas potências aliadas e ampliar a noção de "governados" para além do território de exercício direto da autoridade, a fim de abranger a opinião pública internacional.

A identidade de interesses do Estado líder com seus aliados era principalmente garantida, durante a Guerra Fria, pela "contenção", em primeiro lugar, da União Soviética. Isto se amplia desde a Doutrina Truman, de 1947, e do memorando 68 do Conselho de Segurança Nacional, de 1950, para abranger o bloco soviético, a China, dentro ou fora do bloco, os países e partidos comunistas e seus "assemelhados", movimentos e governos nacionalistas. A "contenção" permitia afirmar que "os valores norte-americanos são universais" (Rice, 2001), compartilhados com o mundo livre.

Desconhece-se o caso de políticas imperiais que não expressam seu nacionalismo por "universais", mas o ponto mais relevante aqui é que a "universalidade" não está mais garantida - há de ser conquistada pela prática de persuasão ideológica, e nisto o entendimento de Rice é de um otimismo anacrônico, revelando também a "arrogância do poder".

Por outro lado, o "interesse" - cujo objetivo final é alcançar ou manter a primazia - já não se defronta com o estorvo comunista e tem, agora, como o desejava o presidente Kennedy, o mundo como a "Nova Fronteira".

O problema principal, e a que se voltará, não é, pois, o “interesse" - por importantes que sejam as divergências - mas a "fórmula política", o "universal" em sua forma concreta.

Em trabalho anterior, intentei, a propósito do governo Clinton, dar conta de como ele tentou conciliar interesse e legitimidade em contraste com o contex- 
to da Guerra Fria (Guimarães, 2000). O objetivo do estudo era antes a rationale do que as políticas, ainda que as principais fossem brevemente analisadas.

Para começar pelo fim, é inequívoco o sucesso da política externa de Clinton entre o público americano. Em 1998, meados de seu segundo mandato, a pesquisa de opinião pública realizada quadrienalmente pelo Chicago Council ou Foreign Relations revelava que ele passava a ser considerado o "mais bem-sucedido" presidente em política externa dentre os dez primeiros mandatários do pós-guerra. Fora classificado em oitavo lugar em 1994. A pesquisa envolvia subamostras de elites e massas (Rielly, 1999). Nada mal; não foi a política externa de Clinton que levou os democratas à derrota de 2000.

Como é sabido, Clinton inicia seu governo enfrentando incômodas situações externas. Em janeiro de 1993, fuzileiros estavam na Somália; executava-se um embargo no Haiti; a Força Aérea bombardeava o Iraque - algo que se tornará um hábito - e preparava-se para intervir na Bósnia. Além disso, seu primeiro governo - e os republicanos obtêm maioria congressual em 1996 - é logo acoimado de pouca clareza conceitual em política externa ou, alternativamente, de uma excessiva dedicação às questões de comércio. Para citá-lo mais uma vez, é um artigo de Huntington (1997) que expressa com clareza a crítica ao economicismo, em detrimento das questões mais amplas de "interesse nacional" - ou seja, estratégicas - de que o governo se deveria ocupar.

A Assessoria para a Segurança Nacional foi, na ocasião, encarregada de formular extenso documento dedicado à "Doutrina Clinton", parcialmente já expressa em vários pronunciamentos desde a campanha eleitoral: "A national security strategy of engagement and enlargement" (1996) (2).

A nova fórmula para conciliar o "particular" (o interesse) e o "universal" (a adesão ou a aquiescência legitimadoras) amplia a doutrina de segurança nacional para além da esfera militar. A este objetivo (principal instrumento anterior da "contenção", mas agora também modificado), acrescentam-se "a revitalização da economia americana" e a promoção da "democracia no exterior". Os objetivos são correlacionados teoricamente e, o que é mais importante, envolvem um jogo global de ganhos mútuos. É necessário citar:

Nações seguras tendem a apoiar o comércio livre e a manter estruturas democráticas. Nações de mercados livres com economias em crescimento e vínculos de comércio aberto tendem a sentir-se seguras e trabalhar para a liberdade. E Estados democráticos não tendem a ameaçar nossos interesses, inclinando-se a cooperar com os Estados Unidos e a promover o livre comércio e o desenvolvimento sustentado. Esses objetivos são alcançáveis desde que esteja assegurado que a América permanecerá envolvida no mundo e com a ampliação da comunidade de nações seguras, de livre mercado e democráticas (idem).

Já tive oportunidade, no trabalho citado, de indicar o caráter controverso dessas proposições. Cumpre acrescentar a elas as noções de crescente interdepen- 
dência entre Estados e de decrescente distinção entre políticas interna e externa - ambas decorrentes de acelerado processo de globalização.

As implicações políticas são evidentes. A paz democrática se afirma, porque nunca foi tão expressivo o número de democracias: free-trade democracies, para usar os termos do documento. O comércio - "doce" desde Montesquieu - aproxima as nações. Só se ganhará com a democratização e o mercado. E os ganhos são de todos os envolvidos, não apenas do Estado líder ("liderança" é dos termos que mais aparece no documento). Por símiles, estes novos Estados inclinam-se à cooperação - o multilateralismo norte-americano se explicita, cooperação que se estende à esfera militar.

O “idealismo" - sempre associado ao presidente Wilson - também se explicita, pois, afinal, é possível fazer agora "um mundo seguro para a democracia”. Há, pois, que promovê-la, e ao comércio, sem descurar da segurança strictu senso, é claro. Fundem-se idéias e interesses, em convergência democrática multiestatal.

Deixando de lado os problemas de persuasão - soft power -, talvez coubesse perguntar pelos inimigos. São poucos, mas perigosos: os rogue states e o que podem mobilizar - o terrorismo, a proliferação de armas de destruição em massa, quando não o envolvimento com o narcotráfico. Os inimigos do primeiro e do segundo Bush são também os de Clinton. São a nova barbárie.

Em relação às políticas, a realidade do mundo freqüentemente se impôs à idealidade conceitual.

No plano econômico, o governo Clinton ressaltou com freqüência seu multilateralismo: a criação do Nafta, da Organização Mundial do Comércio, a ativação da Apec (Cooperação Econômica da Ásia-Pacífico), o incentivo à Alca, para não referir ao que os críticos acoimaram de "pactomania (bilateral) de livre comércio". E isto a despeito de o Congresso negar-lhe o fast-track concedido ao segundo Bush só agora, em 2002.

Um observador entusiasta, em período eleitoral, cita exatamente essas conquistas como evidência do sucesso de Clinton e acrescenta que, a despeito de crises externas - a da Ásia especialmente - "a expansão das exportações respondeu por mais de $20 \%$ do crescimento do Produto Nacional Bruto norte-americano de 1992 a 1999 (Walt, 2000).

O multilateralismo onipresente coexistiu com ganhos expressivos via política econômica. Vigevani e Oliveira (2001), entre outros pontos relevantes, sumariam os aspectos financeiros desta política, que tanto contribuíram para o expressivo crescimento da economia americana no período. Quanto ao multilateralismo, é altamente controverso, para dizer o mínimo, a identificação de interesses entre os participantes da OMC, para não falar dos membros potenciais de uma futura Alca. 


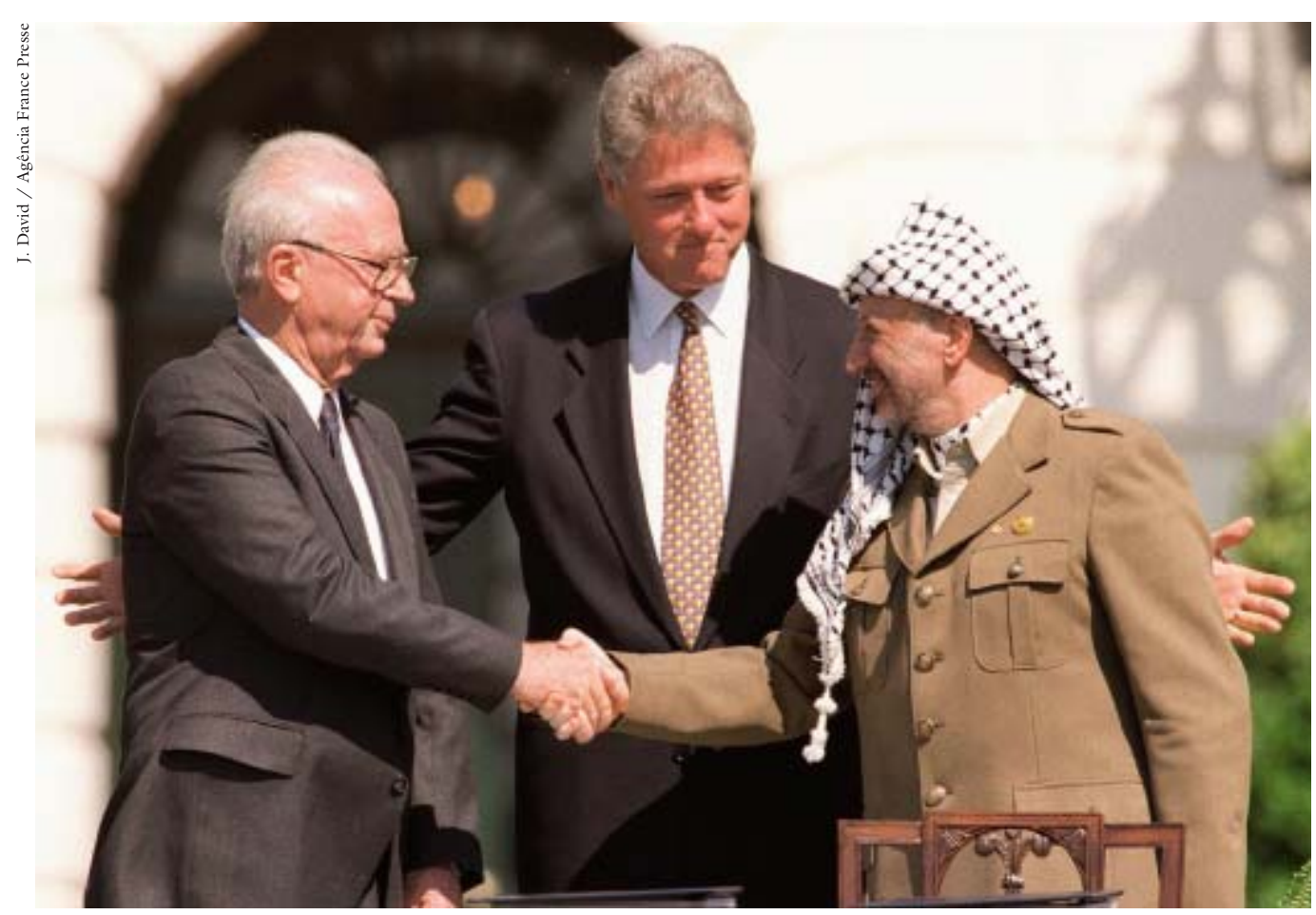

Bill Clinton entre o lider da OLP, $\Upsilon$. Arafat e o ex-primeiro-ministro israelense, $\Upsilon$. Rabin.

O realismo, claro, marca as considerações de natureza militar. Em 2000, como nos anos anteriores, os gastos norte-americanos com a defesa igualavam-se à soma dos dispêndios dos seis países subseqüentes no "ranking" desses gastos.

A redução das tropas norte-americanas no exterior foi grande no pós-Guerra Fria (e a adoção de tecnologia poupadora de mão-de-obra também), mas neste mesmo ano o contingente externo chegava a 257.800 combatentes, com um padrão de distribuição semelhante ao do passado: a parcela mais significativa na Alemanha (69.200), seguida pelo Japão (40.200) e pela região do Golfo Pérsico (29.400) (O’Hanlon, 2001). Aqui também se exalta o grande feito multilateral conferir um novo e permanente sentido à Otan e ampliá-la, recepcionando a República Checa, a Hungria e a Polônia.

Mas o novo sentido da Otan é ambíguo e não escapou a seus críticos europeus, especialmente franceses (Robin, 1995; Joxe, 2002). Não se trataria apenas do velho lugar comum: "manter os Estados Unidos dentro, a União Soviética fora e a Alemanha por baixo", mas de impedir ou neutralizar planos militares autônomos da Europa - por meio da Organização para a Segurança e Cooperação na Europa, por exemplo - e ainda fazê-la contribuir mais pesadamente (como já ocorrera na Guerra do Golfo) para com os custos da "segurança cooperativa".

Como é sabido, o governo Clinton não desautorizou a linguagem de documentos militares sobre a importância fundamental de impedir a emergência de "pares competidores". A China tem sido, por assim dizer, o par de eleição, segui- 
da da Rússia, mas as potências européias podem mirar-se no mesmo espelho - os atritos virão com o sucessor de Clinton.

A renovação do tratado de segurança entre os Estados Unidos e o Japão, em 1995, pode ser entendida como um exercício de "equilíbrio de poder" na Ásia, interpretação não conflitante com a que considera o Japão um "protetorado" americano. Em que medida a Europa, particularmente se agravada pela agressividade do segundo Bush, pode vir a perceber-se em condição similar?

Complicado, portanto, o exercício da primazia benigna em estabilidade unipolar - de fato, impossível para os adeptos das escolas realistas. Daí - e este o mérito de Clinton - o recurso a outras estratégias - a cooperação, o multilateralismo - muitas vezes como retórica, mas não sem eventuais efeitos de adesão.

Grave, contudo, foi um dos feitos do multilateralismo: a intervenção na crise do Kosovo. A Otan substituiu a ONU ao arrepio da lei internacional, esta que Clinton tanto exaltou. Aliança militar de inimigo agora pouco claro, a Otan não detinha prerrogativa legal para a iniciativa. Como todos os termos políticos, multilateralismo é também polissêmico. A ação concertada da Otan no Kosovo, ainda que para evitar atos de genocídio, não se deu no amparo da lei. Predominou o direito do mais forte, abriu-se um precedente para ações similares sem tão nobres motivos. Que multilateralismo? O dos mais fortes? Desconsiderando a ONU? Contra quem?

Afirmar que o governo Clinton pautou-se por uma estratégia de primazia é controverso, particularmente à luz do que vem depois. É talvez adequado explicitar o argumento diante de outras interpretações. Elas estão muito bem explicitadas em notável artigo de Posen e Ross (1966-67), que logo suscitou importante debate sobre as possíveis escolhas estratégicas dos Estados Unidos (Brown, Coté Jr., Lynn-Jones e Miller, 2000).

Posen e Ross assinalam que, no pós-Guerra Fria, quatro grandes estratégias competiriam no discurso e prática da política externa de seu país. A primeira é o neo-isolacionismo (à direita e à esquerda), de pouco impacto, porque derrotada pelos novos argumentos em favor de forte envolvimento externo. As outras são o envolvimento seletivo, a segurança cooperativa e a primazia.

O envolvimento seletivo corresponde à noção tradicional de equilíbrio de poder. O problema principal é assegurar a paz entre as potências. $\mathrm{O}$ foco territorial é a Eurásia. A experiência americana é de forte envolvimento, porque o equilíbrio tende a ser facilitado pela "presença de um líder". O país não pode estar em todo o lugar e comportar-se sempre como o líder onipresente de um mundo unipolar. Nesta tradicional perspectiva dos realistas, a ação em outras áreas requer alianças (a Otan, mas não sua expansão) e cuidado com a emergência de "potências revisionistas" - para usar velha linguagem. Os autores sugerem que muito embora utilizada, falta a esta postura realista a certain romance: repugna àqueles que esposam o idealismo liberal (wilsoniano). Ademais, "seletivo" é um 
termo a que escapam os "problemas conexos", que podem "esticar" o envolvimento para além do previsto.

A segurança cooperativa é de formulação recente, a única que escapa a concepções clássicas dos realistas. De inspiração liberal, propõe que a paz é indivisível. Requer um envolvimento crescente, um "enorme interesse na paz mundial". A cooperação envolve problemas de ação coletiva - e a teoria pertinente de instituições como a ONU ou a Otan. A ampliação da Otan, aliás, foi justificada em termos de segurança cooperativa pela Doutrina Clinton. De resto, dela decorrem os termos mais nobilizantes do envolvimento e da ampliação.

A segurança cooperativa ultrapassa a definição tradicional de "interesse nacional", exatamente porque se trata de forjar instituições multinacionais, reduzindo os custos de dissuasão de agressores e de ameaças emergentes ("custos de transação", para a teoria econômica em que esta perspectiva se fundamenta).

Não é difícil, mais uma vez, perceber a importância desta estratégia na Doutrina Clinton: a cooperação é favorecida porque maior é o número de potências e países democráticos; e é necessária porque a crescente interdependência é a condição do mundo globalizado.

Pequenos conflitos localizados eram irrelevantes em passado recente; agora não o são, porque tendem a expandir-se, magnificados pela mídia, e porque podem envolver o uso de armas de destruição em massa. Verifica-se, assim, uma “interdependência estratégica”, que afeta a segurança dos Estados Unidos e seus aliados, requerendo novas formas de intervenção: por motivos humanitários, operações de paz, ações diante de ameaças difusas; enfim, a concretização do droit d'ingérence.

As críticas não são poucas. Se a paz é indivisível, a noção de segurança é indeterminada. Determina-a apenas o poder definitório que, para relembrar Hobbes, é o poder, simplesmente. Ademais, para retornar a Posen e Ross, os problemas típicos da ação coletiva logo aparecem: por que Estados cooperariam para o bem público?

Há uma solução aqui: os custos da cooperação podem ser reduzidos por uma liderança forte, cujo maior poder militar significasse incorrer em custos mais elevados que aqueles que lhe caberiam - este é o caso de incentivo do sócio maior à ação dos outros. Para ser consistente com a teoria da ação coletiva, a força do líder também se prestaria a uma certa dose de coerção sobre os associados. Mas este é um aspecto que escapou a Posen e Ross.

Finalmente, a primazia é o que é: só a hegemonia garante a estabilidade, a unipolaridade pode e deve ser mantida, a "paz é o resultado de um desequilíbrio de poder”. É preciso, pois, que, para além das necessárias alianças, os Estados Unidos estejam em condições de "intimidar todos os desafiantes potenciais e proteger todos os parceiros". É fundamental localizar os “pares competidores" potenciais que possam ameaçar a supremacia militar, política e econômica dos EUA. 
Ao que parece, a primazia é indivisível, tanto quanto a paz na segurança cooperativa. E em ambos os casos, há compatibilidade com o liberalismo. A promoção da democracia e do mercado contribui para o primado do hegemon. De volta a Huntington: a primazia não objetiva a guerra, mas a evitá-la.

Posen e Ross fazem um balanço da política de Clinton e, algo ironicamente, concluem que sua estratégia foi eclética: uma "primazia seletiva (mas cooperativa)". Ironia ou indecisão teórica à parte, observe-se, em primeiro lugar, que essas estratégias não são excludentes; ou melhor dito: a escolba estratégica pode variar de acordo com o objetivo a alcançar; em segundo lugar, que a necessidade de liderança forte - ou seja de primazia, ao fim e ao cabo - está presente tanto no "envolvimento seletivo", quanto na louvada "segurança cooperativa".

Difícil imaginar alternativa. Os Estados Unidos venceram - e é bom repetilo - venceram a Guerra Fria, em que de resto sempre mantiveram poder superior (claro que não suficiente para a destruição militar do oponente), e é a superpotência inconteste que desfrutará de seu poder enquanto dure. A "primazia" - um eufemismo - se lhe impõe como algo de natural (uma naturalidade historicamente constituída, claro está).

"Prevenir, dissuadir, derrotar" é a vocação militar do hegemon, e a política de defesa de Clinton não foi desatenta ao fato de que poder de Estado e ganho econômico não se tornaram dissociáveis. Os termos do secretário de Defesa do primeiro governo Clinton, que dão início a este parágrafo são bem claros (Perry, 1996).

Clinton valeu-se da linguagem (e da ação) orientada pela primazia quando lhe foi necessário: os aliados a ouviram, a periferia a sofreu, com ou sem multilateralismo. Também é fato que soube temperá-la com as artes do soft power - angariando consensos, particularmente quando a "segurança cooperativa" (e outras formas de cooperativos empreendimentos) foi invocada. Poderosa interpelação que criou, entre os aliados mais importantes e em não poucos espaços periféricos, o que se poderia denominar "partidos da cooperação", reproduzindo adesões típicas do período da Guerra Fria e que se poderia imaginar não mais serem possíveis. Certos entusiasmos chegaram à desmesura, quando, por exemplo, um chefe de Estado da periferia propôs “relações carnais" entre seu país e os EUA.

É interessante que seja exatamente este discurso da cooperação, do idealismo, do multilateralismo o objeto das mais fortes críticas dos republicanos, nas palavras da campanha de George W. Bush e nas ações de seu governo.

O enunciado do oposto aparece, desde logo, e com notável clareza, no já citado artigo de Condoleezza Rice. A hora é de promover os "interesses nacionais". Tanto estes quanto valores e ideais requerem poder para confrontar os que se lhe opõem. Beneficiar a humanidade "é um efeito de segunda grandeza": intervenções humanitaristas devem ser raras. "Acordos e instituições multilaterais não devem constituir fins em si mesmos", como teria ocorrido freqüentemente com Clinton. A alavanca da prosperidade está em adequada política econômica - 
que beneficia a todos os associados porque fortalecem a economia líder, mas o primeiro requisito para a prosperidade é a "paz", que se traduz, no artigo, por um longo excurso sobre a preparação militar e a modernização das Forças Armadas.

A China é um "concorrente estratégico", e a política para a Rússia - insinua-se - deve ser debilitá-la, engajando lideranças regionais e fortalecendo os novos Estados independentes da antiga União Soviética. Os "regimes párias" serão tratados com firmeza e a expressão "obliteração nacional" aparece como ameaça a qualquer tentativa de uso de armas de destruição em massa. Isto é seguir uma "linha internacionalista", mas com "base sólida de interesse nacional" e não "dos interesses de uma comunidade internacional ilusória".

Temos, pois, o fim das ilusões, até porque, como se lê no outro artigo de campanha, na mesma edição de Foreign Affairs, "uma das principais tarefas do próximo presidente dos Estados Unidos será arregimentar o apoio do povo para uma estratégia que moldará o mundo de forma a proteger e promover os interesses e valores dos Estados Unidos nos próximos 50 anos" (Zoellick, 2001) (3). Simples. É o suficiente como concepção a implementar.

Adam Smith ensinou que não se deve contar com a boa vontade do padeiro (e outros fornecedores) para obter a refeição nossa de cada dia. Contudo, o padeiro não diz ao freguês que vende seu pão pelo lucro que obtém. Prefere referir-se à boa qualidade do produto. É dela - a qualidade dos feitos do governo de George W. Bush - que cabe agora tratar.

As marcas fortes da política externa dos longos 17 meses do governo de George W. Bush bem correspondem ao tom de sua campanha. Para uma de tantas análises do pós-11 de setembro de 2001 - cujo significado se explorará adiante - "à parte um desdém explícito por certos acordos multilaterais e uma fixação no sistema antimísseis", o segundo Bush não se afastou muito dos seus antecessores em política externa, até porque o foco inicial foram as dificuldades econômicas internas que já se manifestavam. É o 11 de setembro que produz alterações dramáticas na conduta da política exterior (Walt, 2001-02).

É um ponto do presente trabalho a continuidade da política de primazia de Clinton a Bush. Mas não o é menos as diferenças de entendimento e execução desta estratégia entre os dois governos. É fato que o pós-11 de setembro modifica as políticas de Bush, mas apenas no sentido de agravar uma tendência.

Em sua análise dos primeiros sete meses do governo, Vigevani e Oliveira (2001) procedem o meticuloso levantamento da "diferença", que julgo valer citar por extenso:

Como conclusão, diante dos acontecimentos internacionais patrocinados pelo governo G. W. Bush desde sua posse - tais como o bombardeio do Iraque, a expulsão de diplomatas russos dos Estados Unidos; passando pela rejeição do Tratado de Kyoto e outras medidas antiambientalistas; a busca pelo reforço da posição norte-americana diante da Europa, apesar 
do discurso da parceria; a elevação da Rússia e da China à condição de competidoras estratégicas; a busca pelo rompimento de acordos estratégicos, como o ABM, para a criação do sistema nacional antimísseis; as pressões para a aceleração da Alca; a crise com a China; o isolamento na busca do acordo de paz entre Israel e Palestina, entre outros - pode-se afirmar que vem se implementando um novo perfil unilateral, agressivo e ofensivo na condução da política externa americana que tem transformado a forma de os Estados Unidos exercerem sua liderança neste início de século, a qual é contraposta ao perfil verificado no governo Clinton.

A maior parte das medidas são cristalina concretização do artigo programático de Condoleezza Rice. O programa será aperfeiçoado nos meses subseqüentes.

Observe-se, em primeiro lugar, a tomada de distância em relação a temas supranacionais, da "boa globalização", como a questão ambiental: à rejeição do Tratado de Kyoto, sob alegações várias - em especial, que prejudica as indústrias americanas - já agora se soma o desinteresse do presidente em comparecer à Cúpula da ONU sobre o Desenvolvimento Sustentável (Rio + 10), realizada em agosto de 2002 em Johannesburgo ( $O$ Globo, 17/8/2002), em intuito claro de menoscabar o evento. Ainda nesta esfera, mais grave é a postura quanto aos direitos humanos. Difícil ao país, cujo Departamento de Estado produz relatórios sobre os desrespeitos alhures, recusar-se a aceitar, a não ser sob condições que equivalem a uma recusa, o Tribunal Penal Internacional, o que provocou reações de repulsa na Europa e declarações inconformadas do governo alemão ( $O$ Globo, $8 / 7 / 2002)$. O governo americano foi voto vencido no Conselho Econômico e Social da ONU, quando tentava impedir a aprovação de um protocolo que instituiria a visita de observadores a cárceres de todo o mundo para investigar a prática da tortura - a prisão de Guantánamo, em que vêm sendo recolhidos reais ou supostos integrantes da Al Qaeda poderia ser visitada ( $O$ Globo, 25/7/2002): não são considerados prisioneiros de guerra, não se conhece seu número exato, nem seus nomes, nem os crimes de que são acusados. As reações contrárias provêm agora até mesmo de setores da opinião pública norte-americana.

A batalha contra o protecionismo alheio persiste - e o contencioso com a Europa é crescente. A Otan vê-se mobilizada para possível invasão do Iraque, que nenhum país europeu - salvo a fiel Inglaterra - julga necessária ou conveniente. O governo Bush, apesar da freqüência da visita aos beligerantes, persistiu na sua política de deixar a Israel o trato com os palestinos - e o governo Sharon vem reduzindo cidades a escombros, respondendo aos atos de terrorismo de palestinos radicais com o que já cabe chamar de práticas genocidas. Na origem desta política, aliás, está uma das lamentáveis justificativas do terror do 11 de setembro.

Os tratados sobre o desarmamento vêm sendo desrespeitados ou denunciados, é bem verdade que com contribuição não apenas do atual governo, mas de anterior (Conesa e Lepick, 2002). O presidente W. Bush denunciou expressamente o ABM (Tratado sobre Mísseis Antibalísticos) no ano em curso. O Con- 
gresso não ratificou o CTTB (Tratado de Banimento de Testes Nucleares), e o governo não deseja qualquer revisão a respeito, reservando-se-lhe o direito de realizar testes, se lhe convier. O velho Tratado de Não-Proliferação passou a ter interpretação singular: Irã e Iraque são signatários e, contudo, "maus proliferadores". O Paquistão também o assinou, mas não há críticas americanas. Haveria "bons proliferadores"?

A preocupação com armas de destruição em massa em mãos alheias é crescente. A Convenção sobre Armas Biológicas é de 1972, e os Estados Unidos foram signatários, mas não há sistema de verificação. Propostos, foram rejeitados pelo governo americano em 2000 (ainda sob Clinton) a pretexto de interesses comerciais e de segurança - supostamente o desenvolvimento de antídotos... A Convenção sobre Armas Químicas, de 1993, contém um sistema de verificação (4), e os Estados Unidos o ratificaram com provisões tais que enfraqueceram grandemente seu alcance. Tais provisões restritivas foram subseqüentemente adotadas, nos mesmos termos por outros países: Iraque, Irã, Rússia e... Coréia do Sul. Os Estados Unidos também não concordaram com a Convenção Internacional Antiminas, de 1997. Enfim, os impulsos de antidesarmamento não são apenas do atual governo, mas George W. Bush deu notável contribuição à tendência.

A expectativa de desagrado com o governo de George W. Bush na Europa, na Ásia, nas Américas já era matéria de análise desde o início de seu governo (Bergsten, 2001; Hakim, 2001), mas é evidente, a esta altura, que, a despeito da solidariedade quando do 11 de setembro, George W. Bush passou a contar apenas com linguagem da força como seu meio de comunicação.

A estranha e quase orwelliana "paz" de Condoleezza Rice condensou-se na reação à violência terrorista que provocou centenas de mortes no World Trade Center e à inaudita provocação do ataque ao Pentágono. As bravatas de Bin Laden, antigo aliado (como de resto o foi Saddan Hussein), e de sua Al Qaeda concretizaram-se em realidade trágica. A justa indignação e o desejo de imediata reparação afetariam qualquer governante - e seu povo - especialmente em nação pouco afeiçoada à violência externa em seu próprio solo.

O presidente George W. Bush, contudo, reagiu de forma brutal, não lhe faltando, no primeiro momento, a alusão a uma "cruzada" contra o terror. O termo foi abandonado, mas o etnocentrismo antiislâmico, de há tanto cultivado, logo manifestou-se interna e externamente. Contido a tempo, permitiu a coalizão - de que participaram países islâmicos - que efetuou missão punitiva no Afeganistão: a derrubada do governo dos talibãs (também antigos aliados) e a "caçada" a Bin Laden e a Al Qaeda, que prossegue.

O maniqueísmo incorporou-se à formulação política: quem não está comigo sofrerá punição, fórmula repetida agora na planejada invasão ao Iraque. A este elemento emocional, contudo, adicionou-se a rationale ainda mais ameaçadora. O inimigo não é propriamente Bin Laden, a $\mathrm{Al}$ Qaeda, os talibãs, mas o terror. 
O terror, no entanto, não é uma coletividade humana concreta contra a qual se guerreia, mas uma forma de guerrear. Como tal é espacialmente indeterminado, está em qualquer lugar, e assim foi dito e o tem sido pelas autoridades americanas, que se impuseram a obrigação e se arrogaram o direito de combatê-lo onde bem convier. Quando a indignação se transforma em conveniência, entrase no campo da Realpolitik, neste caso por meio do militarismo e da repressão.

Em indignada reação ao terrorismo, um analista deixou escapar: "a primazia engendrou sua nêmesis" (Ajami, 2001). Sim, mas apenas no imaginário ou, mais especificamente, na interpelação assujeitante que o terror propiciou ao governo de George W. Bush para reafirmar a primazia manu militari.

O terror como instrumento de guerra não foi alheio à atuação militar norte-americana desde há muito. Os que agora o utilizam são velhos aliados desavindos. Há como reduzi-lo: "parem de participar do terror” (Chomsky, 2002).

Entretanto, o terror como abstração efetiva tornou-se verdadeiro "utensílio" do poder. Donald H. Rumsfeld (2002), secretário de Defesa, apresenta em seu programa de "revolução nas questões militares" enorme aumento das despesas militares (com um "enfoque empresarial"), a mobilização de "todos os elementos do poder nacional", a guerra preventiva, enfim, o que mais parece um Estado-guarnição, a partir exatamente desta abstração: "Nosso desafio [consiste em] defender nossa nação contra o desconhecido, o incerto, o não-visto, o inesperado". É preciso ser capaz de "dissuadir e derrotar adversários que ainda não emergiram para desafiar-nos".

Abstração paranóica? Não. Estímulo à paranóia para usos políticos.

"Dezenas de milhares de terroristas treinados estão à solta. Estes inimigos têm o mundo inteiro como campo de batalha e devemos persegui-los onde quer que estejam." A eles e aos rogue states, que são o "eixo do mal". Para isso, "meu orçamento inclui o maior aumento em despesas com defesa das últimas duas décadas" (Bush, 2002).

Todo lugar é também aqui. Ao militarismo soma-se a repressão, com a concentração de todos os órgãos de segurança num superórgão: o projetado Departamento de Segurança Interna, cuja justificativa insinua restrições a liberdades fundamentais (5).

Finalmente, o terror presta-se a reduzir a importância de dificuldades econômicas e da descoberta de que a expressão clony capitalism é, afinal, realmente norte-americana, com a espantosa sucessão de escândalos empresariais.

Não há a menor dúvida de que o século passado foi de fato o "Século Americano" e que a elite dos Estados Unidos está em condições excepcionais para prolongar esta privilegiada situação. Especialmente a partir do final da Segunda Guerra, esta elite competente soube valer-se de um contexto favorável para notável expansão econômica, política e cultural, amparada por formidável poderio militar. É a isto que o termo "primazia" pode referir. Foi este o projeto na- 
cional norte-americano: a expansão da economia de mercado sob sua liderança.

Não são mais apenas intérpretes marxistas, historiadores revisionistas ou pensadores críticos que aludem à "contenção" da Guerra Fria como subsidiária e útil à realização do efetivo "interesse nacional”. Que a bipolaridade daquele período foi "assimétrica" é lugar comum em análises canônicas. Erros houve, é claro: o envolvimento e a derrota do Vietnã, a tardia aproximação com a China, desavinda com a União Soviética desde os anos de 1960. Mas os acertos foram maiores e a "primazia" não foi abalada então, como não o tem sido agora: é tempo de abandonar a noção de pós-Guerra Fria como um novo período histórico para os Estados Unidos. Os elementos de continuidade avultam como mais importantes do que os de mudança.

O presidente Clinton agiu como se tivesse plena consciência deste processo. A dosagem certa de coerção e persuasão deu foros (os possíveis) de legitimidade à ordem continuada, na ausência do inimigo que garantia a coesão de um mundo que é agora bem mais amplo.

Uma elite não é uma clique que, em articulação momentânea, se assenhora do poder com uma visão restrita do "estado do mundo". A luta contra o terror, a primazia como mera hegemonia militar e arrogante, reduz a legitimidade da hierarquia mundial.

Comentando o susto por que passaram os franceses com o desempenho de Le Pen no primeiro turno das recentes eleições presidenciais, Paul Krugman (2002) observa que, afinal, suas ambições se dissiparam e suas idéias extremadas não têm chance de serem postas em prática. E lamenta, em dura crítica, que gente parecida esteja governando seu país. Krugman é politicamente um liberal no sentido que o termo adquire nos Estados Unidos - e expressa o que vai se tornando opinião crescente em seu país, decerto que entre elites relevantes. A primazia norte-americana é negativamente afetada pelo extremismo - se assim é, este durará menos do que se imagina.

\section{Notas}

1 A responsabilidade pelas traduções são do autor do presente trabalho.

2 "Uma estratégia de segurança nacional de envolvimento e ampliação." O documento teve edições posteriores com título novo: "A national security strategy for a new century", mas sem alterações de importância.

3 Vigevani e Oliveira (op. cit.) resumem e desconstroem esta plataforma de campanha.

4 Por meio da OPCW (Organização para a Proibição de Armas Químicas), da qual foi afastado, este ano, seu diretor geral, o embaixador José Maurício Bustani, por pressão americana. A organização preparava fiscalização séria no Iraque e, provavelmente, extinguiria um dos pretextos para intervenções americanas. 
5 O texto completo encontra-se em www.whitehouse.gov/deptofhomeland/ sectl.html.

Referências bibliográficas

"A national security strategy of engagement and enlargement". Casa Branca, fev. 1996, 48 p., http://www.faz.org/ssp/military/ docops/national/1996stra.htm.

AJAMI, Fonnad, “The sentry's solitude”, Foreign Affairs. v. 80, nº 6, nov./dez. 2001.

BERGSTEN, C. Fred., “America's two-front economic conflict”. Foreign Affairs, v. 80, $\mathrm{n}^{\mathrm{o}} 2$, mar./abr. 2001.

BROWN, Michael E.; COTÉ JR., Owen R.; LYNN-JONES, Sean M. e MILLER, Steven E., America's strategic choices. Cambridge: An International Security Reader, The MIT Press, rev. ed., 2000.

BUSH, George W. www.whitehouse.gov/news/releases/2002/01/200201/29-11.html.

CHOMSKY, Noam, “A nova guerra contra o terror”. Estudos Avançados, v. 16, n 44, 2002 .

CONESA, Pierre e LEPICK, Olivier, "Threats to disarmament and international security. The new world disorder”. Le Monde Diplomatique, jul. 2002, MondDiplo.com/2002/ $07 / 05$ treaties.

GUIMARÃES, Cesar, "Envolvimento e ampliação: a política externa dos Estados Unidos", in Samuel Pinheiro Guimarães (org.), Estados Unidos. Visões Brasileiras. Brasília: Instituto de Pesquisa de Relações Internacionais, Fundação Alexandre de Gusmão, 2000 .

HAKIM, Peter, “The uneasy Americas”. Foreign Affairs, v. 80, n 2, mar./abr. 2001.

HUNTINGTON, Samuel P., "Why international primacy matters". International Security, v. 17, n $4,1993$. $\mathrm{n}^{\circ} 5$, set./out. 1997. "The erosion of american national interests", Foreign Affairs, v. 76,

JOXE, Alain, L'empire du chaos. Les républiques face à la domination américaine dans l'apré-Guerre Froide. Paris: Éditions La Découverte, 2002.

KAPSTEIN, Ethan B. e MASTANDUMO, Michael, Unipolar politics. Realism and state strategies after the Cold War. New York: Columbia University Press, 1999.

KRAUTHAMMER, Charles, "The unipolar moment", Foreign Affairs, v. 70, n 1, 1991.

KRUGMAN, Paul, "The angry people", The New York Times, 23/04/02.

O'HANLON, "Come partly home, America", Foreign Affairs, v. 80, n 2, mar./abr. 2001.

PERRY, William J., "Defense in an age of hope", Foreign Affairs, v. 75, n 6, nov./dez. 1996. 
POSEN, Barry e ROSS, Andrew L., "Competing visions for US grand strategy". International Security, v. $21, \mathrm{n}^{\circ}$ 3, 1996-97.

RICE, Condoleezza, "Promovendo os interesses nacionais", Política Externa, v. 10, no 1, jun./jul./ago. 2001 (tradução de Klauss Brandini Gerhardt).

RIELLY, John E., "Americans and the world: a survey at century's end”, Foreign Policy, $\mathrm{n}^{\mathrm{o}} 114,1999$.

ROBIN, Gabriel, “A quoi sert l’Otan”, Politique Étrangére, v. 1, 1995.

RUMSFELD, Donald H., "Transforming the military", Foreign Affairs, v. 81, n 3, mai/jun. 2002.

VIGEVANI, Tullo e OLIVEIRA, Marcelo Fernandes de, "A política externa norteamericana em transição: de Clinton a George W. Bush", Politica Externa, v. 10, n 2, set./out./nov. 2001.

WALT, Stephen M., “Two cheers for Clinton's foreign policy”, Foreign Affairs, v. 79, $\mathrm{n}^{\mathrm{o}} 2$, mar./abr. 2000.

"Beyond Bin Laden", International Security, v. 26, n 3, 2001-02.

ZOELLICK, Robert B., "Uma política externa republicana”, Política Externa, v. 10, n 1, jan./jul./ago. 2001.

RESUMO - O ARTIGO sugere que, com a vitória dos Estados Unidos na Guerra Fria, sua política de expansão adquiriu uma dinâmica mais fácil e mais acelerada. Contudo, a velha noção de "contenção" do comunismo perdeu seu caráter de legitimação da política externa norteamericana. O conceito de "primazia" passou a fazer parte das análises sobre o novo contexto; mas é evidente que a realidade da primazia requeria alguma legitimidade. O governo Clinton foi uma bem-sucedida experiência de primazia. Em comparação, a política externa do atual governo significa um retrocesso, por sua ênfase militar, sua constante demonstração de "arrogância do poder" e pelas conseqüências repressivas internas. Trata-se de um extremismo e é provável que a elite norte-americana não o tolere por muito tempo.

ABSTRACT - THE ARTICLE suggests that, with the victory of the United States in the Cold War, its expansion acquired an easier and more vigorous dynamics. The notion of "primacy" entered into the vocabulary of the analysis of the new context. However, it became obvious that the reality of primacy required legitimacy. Clinton's government was a well-succeeded experience of "primacy". By contrast, the foreign policy of George W. Bush implies a retrocession, because of its military policies, its "arrogance of power" and its internal repressive consequences. It is an extremism: the american elite will not tolerate it for a long time.

Cesar Guimarães é professor do Instituto Universitário de Pesquisas do Rio de Janeiro (Iuperj). 